\title{
PENINGKATAN PENGETAHUAN IBU-IBU PKK DI DESA BULANG DALAM PENGOLAHAN JAHE BUBUK INSTAN SEBAGAI ISIAN KLEPON
}

\author{
Mulyono $^{1}$, Nur Fatmawati ${ }^{2}$, Miftakhul Rohmah ${ }^{3}$, Evi Yunitasari ${ }^{4}$, Lolita Larasati ${ }^{5}$ \\ 1,3,4,5 Fakultas Keguruan dan Ilmu Pendidikan (FKIP), Universitas PGRI Adi Buana \\ ${ }^{2}$ Fakultas Ekonomi, Universitas PGRI Adi Buana \\ Email: Atik.septem@gmail.com
}

\begin{abstract}
Bulang village is one Prambon One village in the district, Sidoarjo regency. Some businesses Namely society has many souvenir shops Typical klepon Bulang village. Activities that can be done to review increasing knowledge PKK is pengolahaan TOGA And to Adding innovation and creativity as the Biodiversity Variation cake klepon to review the utilization of the findings of Plant TOGA Namely ginger instant powder for a review to inform as increase knowledge shown to the PKK , Its activities KKN PPM method used is Demonstrations Namely deliver material and practice. Target Success junlah Trainees can be said to be Good. Training goal achievement can be said to be good. There is an increased knowledge of participants about Processing From the instant powdered ginger as stuffing klepon. Target Achievement Yang has planned material can be said to be very good. Participants ability hearts penguasan Good material. Submission of materials with Demonstration And Also Participants Participate practice.
\end{abstract}

Keywords: Instant Ginger Powder, Klepon, Mothers PKK Bulang village.

\section{PENDAHULUAN}

\section{Analisis Situasi}

Pada zaman modern seperti saat ini, ilmu pengetahuan telah berkembang pesat. Ilmu pengetahuan yang dapat diakses secara mudah dan tidak terbatas dengan berbagai jenis teknologi yang bertujuan untuk meningkatkan pengetahuan masyarakat akan informasi yang dibutuhkannya. Hal ini dapat menjadi tantangan tersendiri dan hal baru bagi ibu-ibu PKK. Maka dari itu, saat ini diperlukan adanya suatu inovasi kegiatan untuk meningkatkan pengetahuan ibu-ibu PKK. Tidak hanya untuk meningkatkan pengetahuan tetapi dapat dipraktekkan dalam kehidupan sehari-hari. Sehingga dapat meningkatkan kesejahteraan keluarga maupun di wilayahnya melalui pemanfaatan dan pengolahan hasil lingkungan di sekitarnya.

Kegiatan yang dapat dilakukan untuk meningkatkan pengetahuan ibu-ibu PKK adalah pengolahaan TOGA. Taman Toga adalah Tanaman Obat Keluarga tanaman hasil budidaya rumahan yang berkhasiat sebagai obat. Sebidang tanah, baik dihalaman rumah, kebun ataupun ladang yang digunakan untuk membudidayakan tanaman yang berkhasiat sebagai obat dalam rangka memenuhi keperluan keluarga kebun obatobatan. Hasil tanaman toga tersebut lalu diolah menjadi TOGA Instan yang dapat digunakan secara praktis dan mengurangi tingkat kebusukan jika pada saat panen menumpuk yaitu salah satunya adalah jahe bubuk instan. Jahe (Zingiber officinale Rosc.) merupakan rempah-rempah Indonesia yang sangat penting dalam kehidupan sehari-hari, terutama dalam bidang kesehatan. Jahe merupakan tanaman obat berupa tumbuhan rumpun berbatang semu dan termasuk dalam suku temu-temuan (Zingiberaceae). Jahe berasal dari Asia Pasifik yang tersebar dari India sampai Cina. (Paimin, 2008). Jahe bubuk instan dimanfaatkan sebagai isian kue tradisional yaitu klepon. klepon merupakan salah satu jenis kue tradisional indonesia yang termasuk dalam kelompok jajanan pasar yang memiliki rasa manis dan gurih. 
Desa Bulang merupakan salah satu desa di kecamatan Prambon, kabupaten Sidoarjo. Beberapa masyarakat memiliki usaha yaitu banyaknya toko oleh-oleh klepon khas desa Bulang. Berdasarkan hasil survey yang kami laksanakan di beberapa toko klepon, semua yang dijual memiliki kemiripan yaitu pada isian. Pada umumnya isian klepon, gula merah. Untuk menambah inovasi dan kreatifitas sebagai keanekaragaman variasi kue klepon dan sebagai pemanfaatan hasil tanaman TOGA yang dilaksanakan oleh divisi Tanam TOGA. Maka dari itu, kami perlu menginformasikan sebagai peningkatan pengetahuan kepada ibu-ibu PKK oleh TIM KKN PPM 2017 Universitas PGRI Adi Buana yang berlokasi di Desa Bulang untuk melakukan pengabdian dengan judul "Peningkatan Pengetahuan Ibu-Ibu Pkk Di Desa Bulang Dalam Pengolahan Jahe Bubuk Instan Sebagai Isian Klepon."

2. Landasan Teori

a) Pengolahan Jahe Bubuk Instan

Jahe (Zingiber officinale (L.) Rosc.) mempunyai kegunaan yang cukup beragam, antara lain sebagai rempah, minyak atsiri, pemberi aroma, ataupun sebagai obat (Bartley dan Jacobs 2000). Secara tradisional, kegunaannya antara lain untuk mengobati penyakit rematik, asma, stroke, sakit gigi, diabetes, sakit otot, tenggorokan, kram, hipertensi, mual, demam dan infeksi (Ali et al. 2008; Wang dan Wang 2005; Tapsell et al. 2006). Berdasarkan bentuk, warna, dan ukuran rimpang, ada 3 jenis jahe yang dikenal, yaitu jahe putih besar/jahe badak, jahe putih kecil atau emprit dan jahe sunti atau jahe merah. Secara tradisional ekstrak jahe digunakan antara lain sebagai obat sakit kepala, obat batuk, masuk angin, untuk mengobati gangguan pada saluran pencernaan, stimulansia, diuretik, rematik, menghilangkan rasa sakit, obat anti-mual dan mabuk perjalanan, karminatif (mengeluarkan gas dari perut) dan sebagai obat luar untuk mengobati gatal digigit serangga, keseleo, bengkak, serta memar (Shukla, 2007).

Jahe bubuk instan merupakan hasil olahan dari jahe yang bertujuan untuk meningkatkan nilai jual beli jahe, dan memudahkan dalam penggunakan jahe itu sendiri agar mudah dikonsumsi. Instan jahe tidak berwarna putih tapi agak keruh ini diperkirakan pengaruh dari warna jahe yang kita gunakandan gula yang terlarut pada sari jahe. Instan jahe ini juga rasa nya masih terasa pedas, dan untuk rasa manisnya berasal dari gula pasir. Pada pembuatan atau pemrosesan jahe menjadi jahe instan/bubuk di butuhkan waktu kurang lebih 30 menit tergantung banyaknya yang diolah. Pembuatan jahe instan ini cukup lama dan ketelitian dalam mengaduknya sampai menjadi bubuk kasar dan mengayaknya. Pengayakan ini di lakukan agar bubuk halus dan bubuk kasar terpisah.

Proses pembuatan jahe bubu instan adalah sebagai berikut,

1) Kupas dan cuci jahe hingga bersih

2) Parut jahe atau blender jahe.

3) Setelah diparut tambahkan air 1 liter.

4) Selanjutkan peras menggunakan kain tipis saring.

5) Endapkan Parut jahe selama \pm 1 hari.

6) Ambil air sari jahe dan jangan sampai pati endapan terikut.

7) Tuang sari jahe 1 liter ke wajan dan masukkan gula pasir $1 \mathrm{~kg}$

8) Masak diatas kompor dan terus diaduk sampai mengkristal dengan api kecil.

9) Lalu blender dan ayak dengan saringan

10) Toga instan siap dikemas.

b) Klepon

Klepon merupakan salah satu jenis produk pangan tradisional semi basah dan salah satu jenis jajanan pasar yang telah dikenal dan beredar sejak lama di lingkungan masyarakat, khususnya masyarakat di pulau Jawa. Klepon memiliki bentuk bulat-bulat kecil yang dimakan sekali suap, memiliki rasa manis dan gurih, warna klepon biasanya hijau yang berasal dari air daun suji dan berbagai warna sesuai selera, tekstur kulit yang kenyal karena berasal dari bahan tepung ketan. Tepung ketan berasal dari beras ketan putih yang memiliki warna putih, tidak transparan dan telah melalui tahap penggilingan sampai mencapai ukuran granula yang diinginkan (Sudarminto, 2015). Bahan yang digunakan untuk pembuatan klepon adalah tepung ketan, air 
hangat, air kapur sirih yang diaduk atau diuleni hingga. kalis lalu diberi isian gula merah dan direbus sampai terapung lalu digulingkan pada kelapa parut yang telah diberi sedikit garam dan dikukus. Klepon biasa berdampingan bersama getuk dan cenil sebagai camilan sore atau pagi hari.

3. Rumusan Masalah

Beberapa permasalahan yang teridentifikasi di lokasi pengabdian, antara lain:

a) Bagaimana cara meningkatkan pengetahuan tentang Pengoalahan jahe bubuk instan pada ibu-ibu PKK di Desa Bulang?

b) Bagaimana cara meningkatkan pengetahuan tentang isian klepon dari jahe bubuk instan pada ibu-ibu PKK di Desa Bulang?

4. Tujuan
a) Meningkatkan pengetahuan tentang Pengolahan jahe bubuk instan pada ibu-ibu PKK di Desa Bulang
b) Meningkatkan pengetahuan tentang isian klepon dari bubuk jahe instan pada ibu-ibu PKK di Desa Bulang

5. Manfaat

Manfaat kegiatan ini adalah sebagai berikut,

a) Meningkatkan pengetahuan tentang Pengolahan jahe bubuk instan pada ibu-ibu PKK di Desa Bulang

b) Meningkatkan pengetahuan tentang isian klepon dari bubuk jahe instan pada ibu-ibu PKK di Desa Bulang.

c) Ibu-ibu PKK yang menjadi peserta pelatihan dapat menularkan pengetahuan dan keterampilan yang diperoleh secara langsung melalui praktek di rumah kepada para tetangga.

\section{METODE}

1. Khalayak Sasaran Kegiatan

Adapun yang menjadi sasaran dalam kegiatan ini adalah ibu-ibu PKK Desa Bulang Kec. Prambon Kab. Sidoarjo. Target sasaran berjumlah 50 orang.

2. Metode Kegiatan KKN PPM

Metode kegiatan KKN PPM yang digunakan adalah teknik pelatihan dalam pembuatan jahe instan (demonstrasi pembuatan jahe instan). Mahasiswa menyampaikan materi dan mempraktekkan pembuatan toga instan dengan runtun mulai dengan penyampaian alat yang digunakan, bahan, cara pembuatannya dan hasil olahannya. Peran masyarakat ikut serta dalam pelaksanaan kegiatan ini dengan menghadiri acara, melihat demo pembuatan toga instan, mencicipi beberapa olahan toga instan dan mengajukan pertanyaan.

3. Langkah-langkah kegiatan KKN PPM Adapun langkah-langkah yang dilakukan dalam kegiatan KKN PPM ini, adalah sebagai berikut:

a) Permohonan ijin kepada pihak desa tentang pelaksanaan program yang akan dijalankan atau disosialisasikan.

b) Penetapan tempat dan waktu kegiatan pelaksanaan pelatihan.

c) Menyebarkan undangan kegiatan

d) Penentuan sasaran dan target peserta pelatihan.

e) Persiapan Toga, meliputi penyiapan bahan dan alat yang akan digunakan saat demo pembuatan jahe instan.

f) Perencanaan materi, yaitu materi yang akan disampaikan saat demo, materi tentang keterampilan pengolahan toga khususnya pembuatan bubuk jahe instan dan untuk variasi isi klepon.

4. Faktor Pendukung dan Penghambat Kegiatan KKN PPM

Adapun faktor pendukung dan penghambat dalam pelaksanaan kegiatan KKN PPM adalah :

a) Faktor Pendukung

1) Sambutan positif dari pihak perangkat desa terutama Kepala Desa Bulang dalam mendukung pelaksanaan kegiatan ini.

2) Antusias ibu-ibu PKK sebagai peserta pelatihan dimana para ibuibu ikut berpatisipasi, tidak hanya menyimak materi tetapi ikut mempraktekkan saat pelatihan.

3) Dosen pembimbing yang senantiasa memberikan bimbingan, pengarahan, dan dukungan kepada kami agar dapat melaksanakan program dengan baik. 
4) Teman-teman KKN yang saling mendukung dalam pelaksanaan kegiatan.

b) Faktor Penghambat

1) Keterbatasan waktu dalam pelaksanaan kegiatan pelatihan.

2) Kesibukan masing-masing peserta

\section{HASIL DAN PEMBAHASAN}

1. Hasil Pelaksanaan Kegiatan KKN PPM Hasil kegiatan KKN PPM dapat diuraikan melalui 2 (dua) tahap kegiatan yaitu persiapan dan pelaksanaan. Pada tahap persiapan yang merupakan perencanaan program KKN sebagai berikut:

a) Tahap Persiapan

1) Koordinasi dengan pihak desa Bulang

Koordinasi dengan pihak desa dilakukan dengan Kepala Desa

Bulang. Pihak desa mendukung kegiatan yang dilakukan oleh Mahasiswa Universitas PGRI Adi Buana dalam rangka menambah ilmu ibu-ibu PKK di wilayahnya, yakni peningkatan pengetahuan ibu-ibu PKK tentang pengolahan bubuk jahe sebagai isian klepon.

2) Penetapan tempat dan waktu pelatihan

Pelaksanaan pelatihan berdasarkan kesepakatan, yaitu hari Sabtu, tanggal 11 Februari 2017, Pukul 09.00 WIB bertempat di Balai Desa Bulang Kec. Prambon Kab. Sidoarjo.

3) Penentuan sasaran dan target peserta pelatihan

Sasaran dalam kegiatan pelatihan ini adalah ibu-ibu PKK desa Bulang. Sedangkan target peserta dalam kegiatan ini adalah 50 orang.

4) Perencanaan materi dan pelatihan Materi pelatihan yang telah disiapkan dalam kegiatan pelatihan ini adalah cara pengolahan toga menjadi bubuk jahe dan isian klepon

b) Tahap Pelaksanaan

1) Kegiatan KKN PPM dengan judul "Peningkatan Pengetahuan Ibu-ibu PKK Di Desa Bulang Dalam Pengolahan Jahe Bubuk Instan
Sebagai Isian Klepon" yang dilaksanakan pada hari Sabtu, tanggal 11 Februari 2017, Pukul 09.00 WIB.

2) menjadi jahe bubuk instan dan isian klepon telah disampaikan dalam waktu yang singkat.

3) Dalam kegiatan pelatihan diberikan contoh tester berupa minuman yang dibuat dari pengolahan TOGA (Jahe) agar masyarakat mengetahui dengan pasti takaran antara serbuk jadi yang dilarutkan dengan air supaya rasanya tepat dan khasiatnya dapat dirasakan. Dan juga masyarakat, diberikan contoh klepon dengan isian jahe, agar masyarakat mengetahui bagaimana rasanya jika isi klepon dipadukan dengan jahe.

2. Pembahasan Hasil Pelaksanaan Kegiatan KKN PPM

Hasil pelaksanaan kegiatan KKN PPM secara garis besar dapat dilihat berdasarkan komponen di bawah ini yaitu :

a) Keberhasilan target jumlah peserta

Keberhasilan target junlah peserta yang hadir pelatihan dapat dikatakan baik. Dari 50 orang peserta yang diundang sebanyak 28 orang yang hadir mengikuti pelatihan.

b) Ketercapaian tujuan pelatihan

Ketercapaian tujuan pelatihan dapat dikatakan baik. Ada peningkatan pengetahuan dari peserta tentang pengolahan jahe bubuk instan sebagai isian klepon. Peningkatan pengetahuan ibu-ibu PKK di Desa Bulang dalam pengolahan jahe bubuk instan diharapkan dapat terwujud dengan baik melalui pemberian minuman kesehatan berupa serbuk jahe instan yang sudah dikemas di botol dan tester klepon isi jahe, sehingga ketika mereka ingin menyampaikan ke ibu-ibu lainnya bisa ada contohnya.

c) Ketercapaian target materi yang telah direncakan 
Ketercapaian target materi yang telah direncanakan dapat dikatakan sangat baik. Semua materi pelatihan dapat disampaikan oleh mahasiswa KKN PPM 2017 dengan waktu yang singkat namun isinya padat dan mengenah secara keseluruhan.

d) Kemampuan peserta dalan penguasaan materi.

Kemampuan peserta dalam penguasan materi baik. Penyampaian materi dengan demonstrasi dan peserta juga ikut mempraktekkan bersama sangat medukung dalam penguasaan materi yang disampaikan oleh tim mahasiswa.

Secara keseluruhan kegiatan pelatihan "Peningkatan Pengetahuan Ibu-ibu PKK Di Desa Bulang Dalam Pengolahan Jahe Bubuk Instan Sebagai Isian Klepon" dapat dikatakan baik dan berhasil, yang dapat diukur dari keempat komponen di atas

\section{PENUTUP}

1. Kesimpulan

a) Pelatihan "Peningkatan Pengetahuan Ibu-ibu PKK Di Desa Bulang Dalam Pengolahan Jahe Bubuk Instan Sebagai Isian Klepon" dapat meningkatkan pengetahuan ibu-ibu PKK terhadap pengolahan jahe bubuk instan dan hasil olahannya yaitu sebagai isian klepon.

b) Peningkatan pengetahuan bagi ibu-ibu PKK pemanfaatan TOGA sebagai jahe bubuk instan dilakukan dengan metode demonstrasi dan menyediakan hasil bubuk jahe instan yang dikemas dalam toples kecil dan bebrapa hasil olahan seperti klepon dan minuman jahe.

c) Peningkatan Pengetahuan Ibu-ibu PKK Di Desa Bulang di kecamatan Prambon dalam pengolahan jahe bubuk instan sebagai isian klepon dapat dilaksanakan dengan baik, sukses dan tertib.

\section{Saran}

a) Program ini diharapkan dapat dilaksanakan di tempat lain pada tahun berikutnya untuk meningkatkan pengetahuan ibu-ibu PKK dalam pembuatan Toga Instan dan Hasil Olahannya.

b) Perlu adanya penambahan materi pelatihan tentang proses packaging yang baik dan dapat bertahan lama

c) Perlu adanya penambahan materi tentang pembuatan klepon instan.

\section{DAFTAR PUSTAKA}

Ali, B.H., G. Blunden, M. O. Tanira dan A. Nemmar. 2008. Some phytochemical, pharmacological and toxicological properties of ginger (Zingiber officinale Roscoe): A review of recent research. Food and Chemical Toxicology. 46 : 409-420

Bartley, J. dan A. Jacobs. 2000. Effects of drying on flavour compounds in Australian-grown ginger (Zingiber officinale). Journal of the Science of Food and Agriculture. 80:209-215.

Paimin, F. B. Dan Murhanato. 2008. Budidaya, Pengolahan, Perdagangan Jahe. Penebar Swadaya: Jakarta

Shukla, dan Singh. 2007. Cancer Preventive Properties Of Ginger: A Brief Review. J. Food And Chemical Toxicologi.

Sudarminto Setyo Yuwono.2015. Tepung ketan (Oryza Sativa Glutinosa). Darsatop.lecture.ub.ac.id. diakses tanggal 05 Maret 2017.

Tapsell, L.C., I. Hemphill, L. Cobiac, C.S. Patch, D.R. Sullivan, M. Fenech, S. Roodenrys, J.B. Keogh, P.M. Clifton, P.G. Williams, V.A. Fazio dan K.E. Inge. 2006. Health benefits of herbs and spices: the past, the present, the future. Med. J. Aust. 185 (Suppl. 4),S4-S24.

Wang, W.H. dan Z.M. Wang. 2005. Studies of commonly used traditional medicine-ginger. Zhongguo Zhong Yao Za Zhi. 30:1569-157 
ABADIMAS ADI BUANA Volume 01, Nomer 1, 01 Juli 2017 